\title{
Review of mass media effect in inter-cultural communication
}

\author{
Bata Gouda Mohamed Hawali a,1,*, Dietrich Cyrielle ${ }^{\text {b,2 }}$ \\ ${ }^{a}$ University of Abomey-Calavi, 01 BP 526 Calavi, Cotonou, Littoral 1425, Benin \\ ${ }^{\mathrm{b}}$ University of Strasbourg, 4 Rue Blaise Pascal, Strasbourg 67081, France \\ ${ }^{1}$ batagouda@yahoo.com*; ${ }^{2}$ cyrielle.dietrich@gmail.com \\ * corresponding author
}

ARTICLE INFO

Article history

Received 2020-06-16

Revised 2020-06-29

Accepted 2020-07-01

Keywords

Effect

Mass Media

Inter-Cultural Communication

\section{ABSTRACT}

This paper aims to describe how humans communicate with each other is always influenced or in a complex cultural context. Humans learn to think, feel, believe, and work on what is culturally appropriate. Language, friendship, eating habits, communication practices, social actions, economic and political activities, and technology are based on cultural patterns. This paper is the result of library research, where the author conducts academic studies of various relevant reading material. The conclusion in this paper is What people do, how they act, how they live and communicate, are responses to and functions of their culture.

This is an open access article under the CC-BY-SA license.

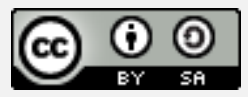

\section{Introduction}

Humans are born into the world without carrying any attribute. In the world, humans get knowledge and experience from their social environment [1]. Knowledge and experience are gradually multiplying and complex [2]. Not only from relationships with his family, but also through peers, groups or other community organizations, and the mass media. Humans begin to be distinguished from other individuals because of the experience and knowledge they have [3]. Relationships between other individuals increasingly internalize patterns of interaction and culture in their environment. Humans have unconsciously studied the state of their background, tried to understand it, and made their property in identifying and having a more specific space and time orientation when dealing with other community groups or cultures [4]. The pattern of interaction that is built and developed by humans is an ongoing learning process. Not only useful for himself but also for the group. Naturally, human individuals will be essential contributors to their groups or even outside the group in the context of social and cultural change. Such individual dynamics influence cultural dynamics in a broader and more open setting [5].

Humans have unique and different biological and psychological dimensions. The desire to survive, reproduction, and self-expression is the fundamental drive of human being [6]s. That primary thrust will be fulfilled through an effective communication process. Communication is not only carried out within the group itself (inside the group) but also with members from other cultural groups (output groups). Thus communication builds and develops culture significantly [7]. Communication guarantees social and cultural dynamics in a society or community concerned. Dialogue is useful in the process of inheriting cultural values of particular populations from one generation to the next through the process of transforming messages that are continuously carried out [8]. The result will give birth to a kind of uniformity patterned on the characteristics and character of the cultural group of the community. Simultaneously, this also provides benefits for the maintenance of cultural patterns that have been accepted by community members, as well as bringing meaningful dynamics. 
Communication, with its various channels such as interpersonal, group, and mass media, makes culture more dynamic and complex. Culture also gives importance to communication. Communication takes place in a socio-cultural context that is almost always different [9]. Humans communicate with each other are always influenced or are in a complex cultural context. Someone determines who will interact with, what things may and may not be conveyed, when delivered, how the possibility of feedback obtained from communication partners, everything is determined and influenced by culture [10]. Likewise, culture determines the way humans choose, package, and decide what symbols they will use to wrap the meaning to be conveyed. Studies of symbols that have recently been studied in the discipline of communication have long been recognized in anthropological studies [11].

Humans can develop and isolate relationships in abstract meaning [12]. Humans as products and users of symbols from a system of signs and symbols that apply as a means of communication to convey knowledge and other messages. Communication is a means to make individuals aware of and adapt to the sub-cultures and foreign cultures they encounter [13]. Culture is formulated, shaped, transmitted, and studied through communication. Human communication behavior is mainly influenced and depends on culture. Through discussion, humans develop culture, and perception determines the rules and patterns of interaction. In anthropological studies, symbols are known as objects, events, speech sounds, or written forms that are given meaning by humans [14]. The primary way of symbolization by humans is through language. But humans not only use language in communication. Humans also use signs and symbols in painting, music, dance, architecture, body posture, fashion, gestures, possession of goods, spatial planning, distances, and others. Humans can give meaning to any event, action, or object related to thoughts, ideas or emotions, and emotions [15].

Humans learn to think, feel, believe, and work on what is culturally appropriate. Language, friendship, eating habits, communication practices, social actions, economic and political activities, and technology are based on cultural patterns. What people do, how they act, how they live and communicate, are responses to and functions of their culture. Continuous and present learning; includes all affirmations of behavior received during a period of life needs. Culture also deals with physical forms and structures as well as the social environment that affect the human environment. Religion can be interpreted as a whole symbol, meaning, depiction (image), the structure of rules, habits, values, information processing and transfer of patterns of thought conventions, words and actions or actions that are shared among members of a social system and social groups in a Public. Culture has given space for communication to be more accessible and more effective. Culture becomes a fundamental element that is very important for ongoing discussion. Culture will not be able to develop widely and be maintained. So that the term culture appears is communication and communication is culture [16].

\section{Theorical Framework}

\subsection{Limitation of the Meaning of Intercultural Communication}

Communication between people is done using verbal or nonverbal messages. Someone who is communicating actually he is behaving. A behavior can be called a message if previously observed by someone, and the behavior contains meaning. Every behavior that can be interpreted is a message. The communication behavior takes place in individual consciousness or not as well as intentional or unintentional. Thus, it is not possible for humans not to behave. It is impossible for humans not to communicate. Communication is a dynamic transactional process that influences behavior in which participants intentionally code their practice to produce messages that are channeled to stimulate or obtain individual attitudes or behaviors. The recipient of the message perceives or understands the encoded behavior, gives meaning to it, and is affected by it. This transaction must include all conscious-unconscious, intentional, inadvertent, verbal, nonverbal, and contextual stimuli that act as signals to the source and recipient about the quality and credibility of the message [17].

Communication is not only done by humans with people from members of the same cultural group. The disclosure also takes place between people from different cultural groups. The existence of differences in the value systems adopted by each culture and nation has the potential to cause a clash of value systems and social conflict in society. Likewise, in the communication process, 
cultural differences become an essential factor in the effectiveness of communication. From this was born the concept of intercultural communication, which was simply interpreted as a process of communication that took place between people of different cultural backgrounds. The progress of science and technology today is increasingly expanding the concept and meaning of intercultural communication. Human relations in the international sphere take place in a variety of contexts and ways. These relationships have the potential to cause crucial problems in shifts, changes, and even pollution of cultural values. Acculturation will occur, even assimilation, that will bring essential changes in the culture of a particular community or country [18]. The ability of people to adapt to new values in their lives is not the same. Intercultural communication is expected to minimize the negative consequences of the relationship, making it more effective and productive. The term intercultural communication has long been used by communication scientists and researchers [19]. This concept is also often discussed in various mass media. Some courses in the communication science department also speak about intercultural communication. There is even a separate subject that specializes in studying intercultural communication in various dimensions, processes and effects [20]. One of the important things discussed in communication studies, including intercultural communication, concerns the use of communication symbols. And one of the symbols known in the communication process is language [21]. In the context of intercultural communication, the use of language is very urgent. Language is considered as the most compelling symbol in the communication process. But the language factor is often the cause of the inequality of meaning over the message conveyed [22].

Today, intercultural communication develops rapidly and intensely. Three factors drive the development of intercultural communication [23], namely (1) international factors; the occurrence of world communication networks due to advances in information and communication technology. An attitude of mutual understanding between nations is needed, through an understanding of other cultures and countries (2) domestic factors; the birth of new mini-sub-cultural groups. Thus excellent intercultural communication is required, and (3) individuals; demand to be able to adapt to other cultures so that anxiety does not occur due to the loss of signs and symbols in social relations (culture shock). Intercultural communication occurs when two or more people with different cultural backgrounds interact. The perpetrators of intercultural communication are usually unaware of their behavior, so it is tough to mark and master both verbal and nonverbal behavior in other cultures. Humans have different life experiences in different cultures; they will interpret differently the same signs and symbols [24].

Humans communicate in various ways that emphasize or deny what they say through words. They learn to read different parts of the communication spectrum [25]. Culture influences communication in many ways. It is the culture that determines the time and schedule of interpersonal events, places to talk about specific topics, the physical distance that separates a speaker from others, and the tone of voice appropriate for a particular conversation [26]. In this case, culture, according to Hall and Whyte, describes the level and type of physical contact that habits require and the intensity of emotions that accompany it. Intercultural communication occurs when the message producer is a member of a culture, and the recipient of the message is a member of another culture [27]. In such circumstances, we are faced with problems that exist in a situation where messages are encoded in one culture and must be encoded in another culture. Culture is assumed to be responsible for the entire vocabulary of communicative behavior and meaning that everyone has [28], consequently, treasuries owned by two people of different cultures will be various, which can cause all kinds of difficulties.

\subsection{Principles of Intercultural Communication}

Several principles are fundamental so that the communication process - including intercultural communication - can run effectively. Lunenburg [29] conclude these principles into three essential principles, namely: (1) A shared cipher system consisting of two aspects - verbal and nonverbal. Lunenburg distinguishes high context culture and low context culture. High-context literature and low-context culture have some critical differences in how the message is encoded. (2) Different beliefs and behaviors between communicating parties are the basis for different assumptions for responding. It may be that two people with different cultures then give different meanings to the same action. (3) The level of knowing and accepting the beliefs and behavior of others. Components, knowledge, and acceptance, are not just knowledge of differences that cause problems, but also the level of acceptance of variations that can cause problems. According to Sarbaugh, the 
way we judge other cultures by our cultural values and refuse to consider different cultural norms determines the effectiveness of the communication.

María Catrileo [30] suggests four requirements for effective intercultural communication. First, we must respect other cultural members as humans; second, we must respect different cultures as they are, not as we wish; third, respecting the rights of other cultural members to act differently from the other ways we work; and four, competent cross-cultural communicators must learn to enjoy living with people from different cultures. María Catrileo further stated that the effectiveness of communication depends partly on the situation and social relations between the communicator and the communicant, especially in terms of reference (reference frame) and the breadth of experience. Intercultural communication studies need to be studied at least for two critical reasons, namely, namely: (1) People are ethnocentric. Human perception is subjective. Ethnocentric is using a culture standard of its own to measure other cultures. The stereotype is a false generalization of a group of people by ignoring their characteristics. A stereotype can lead to a self-fulfilling prophecy, an event that takes place based on predictions (with) that it will indeed happen, and (2) Communication meets human needs. Effective communication makes people happier, healthier, and more successful (including entrepreneurs, managers, business people, executives, and others) [31].

\section{Method}

This paper is the result of library research that the author did. What is meant by library research is research conducted based only on written works, including research results, which have not been published [32]. Although it is research, research with a literature study does not have to go to the field and meet with respondents. The data needed in research can be obtained from library sources or documents. According to Research Information Network, in library research, library search is not only for the initial step of preparing a research framework but also at the same time utilizing library resources to obtain research data [33]. In addition to data, several things that must be present in a study to be scientific, also require other things such as problem formulation, theoretical basis, data analysis, and conclusion making.

Research with literature is research that is the same preparation as other studies but the sources and methods of data collection by taking data in the library, reading, recording, and processing research materials. Although it looks easy, the study of literature requires high perseverance so that the data and data analysis and conclusions produced by the expected goals. This requires optimal preparation and implementation. Research literature studies need a thorough and in-depth analysis to get results. Thus research with literature studies is also research and can be categorized as a scientific work because a strategy does data collection in the form of research methodology. Variables in the study of literature studies are not standard. The data obtained were analyzed in depth by the author. The data collected is poured into sub-chapters so that it answers the research problem formulation.

\section{Results and Discussion}

The Role of Mass Media in Intercultural Communication Humans, society, and culture are valued as three things whose existence explains one another. Culture is assumed to be a product of the human activity, and the individual becomes human because he lives in and contributes to culture. In the process of cultural production activities, the individual together with other individuals and forms a social unit called society. Individuals in their cultural relations are influenced by three main things, namely: the natural (physical) environment, the intuitive environment, and their social environment. These three factors are seen to determine human individuals in developing and interpreting their own culture. Religious systems, for example, significantly affect humans giving meaning to life, which they consider normal, natural, and ethical in society. The religious order as a dimension of trust that develops in the intellectual environment of a community is one of the determinant factors in human culture. For example, Muslims believe that covering certain parts of a woman's body with a headscarf is obligatory, so the clothing industry developed includes the genitalia of a Muslim woman. Likewise, social relations are seen as ethical standards in social interaction, institutionalized in various formal agreements, such as educational institutions. 
But how to dress is influenced by not only the intellectual environment, but also the natural environment. People who live in Europe and East Asia wear thicker clothes because of the frigid temperatures. While those living in more tropical regions such as Southeast Asia and Africa wear thinner clothing, similarly, in terms of food, how to eat, time orientation, and various other living equipment systems, very much determined by the natural environment (geographical). Communication is also influential; people who live in coastal areas tend to speak more senseless when communicating compared to those far from the coast. The social environment is formed from the crystallization of values built through social interaction. This is also very important in the process of understanding and developing human culture. Cultural and social values strongly influence individual communication patterns. The communication method between individuals in a cultural group also changes the dynamics of these cultural and social values. There is a mutually influential relationship between the patterns of communication that take place between members of a cultural group and the cultural and social benefits that exist within the community group concerned. In the phenomenological tradition, culture is considered as a concrete form of social work to build what is called Lebenswelt or the world of life.

Humans distinguish themselves from other living organisms through the formation of Lebenswelt, which in addition, can be inhabited naturally but also socially lived [34]. Because an individual is born with other individuals into a world that has long been built and inhabited by others before. Cultural work is the process of creating a tradition. Individuals can never create culture alone, but rather as limited producers. Human individuals carry out cultural work activities together with other individuals to build their unique world of life. Joint cultural events will occur if effective communication is made. Not just small scale (micro), but also in broader social life (macro). This will be seen more in how the mass media play their role in the process of inheriting the sociocultural values of the next generation of generations. Mass media, as one channel of intercultural communication, brings constructive developments in intercultural life. The context of interpersonal communication has shifted, and there tends to be a decline in patterns and cross-cultural social interactions. Traditional groups in a community or community have characteristics of modes of social communication between members that encourage mutual understanding and interests and allow social interaction. The mass media offers a diversity of new information and knowledge with a huge volume. This encourages the acceleration of knowledge of other cultural characters (outgroups). The higher the human understanding of other cultures, the more effective intercultural communication will be.

Mass media facilitates social interaction for cultural similarity. Information and orientation, facts and values can be known without human interaction. The beliefs of some people who are valued as real and valuable can now be controlled from a distance, apart and outside of those who believe in it. The media instills a sense of willingness to live together in cultural diversity and accepting differences. This facilitates the communication process in interpersonal contexts, even if it is done with people from different cultures. Thus the mass media plays a role in developing, passing down, and preserving culture more broadly and openly. Through mass media, a person can understand the differential aspects of his community group with other cultural groups. According to Edward B. Taylor, culture is a complex whole that contains knowledge, beliefs, arts, morals, law, customs, and other abilities that a person has as a member of society [35]. Bronislaw Malinowski explained four essential elements of culture which include: A norm system that allows cooperation between members of society to adapt to the natural surroundings; Economic organization; Equipment and institutions or officers for education (family is the principal educational institution); and (political) power organizations [36]. Cultural elements in various levels give different colors for each individual as a member of a particular cultural group or community. These elements affect the process of ongoing communication between participants who come from different cultures. Individuals have the highest uniqueness at the level of cultural values that they hold and possess.

Mass media makes it easy for us to communicate between cultures, facts, and values about other cultures we can know without interaction with different cultures. Mass media's existence makes us understand the so-called willingness to live together in cultural diversity and accept differences. With the mass media, if someday we interact with people who will be different from our culture, we are not too confused and have little knowledge about how to communicate between cultures. The mass media also plays a role in developing, passing down, and preserving culture more broadly and 
openly. Through the mass media, people can understand aspects of their community or other culture. Such is the role of the mass media in intercultural communication.

Here are some media influences in intercultural communication: (1) Imitation: In the era of globalization, the phenomenon of imitation is straightforward; many people study foreign cultures that make their own culture eroded and lost. As we know that in Indonesia itself, there has been a lot of imitation. (2) Cultural heterogeneity: The emergence of a variety of new cultures can slowly shift or eliminate cultures that already exist in this world. (3) The development of popular culture: Popular culture is already pervasive in Indonesia; they assume that people who hold their own cultural identity are considered ancient and out of date. (4) The erosion of local culture: As a result of the spread of popular culture, including in Indonesia, the regional culture will eventually be displaced because no generation can continue the culture, and there may be no one who communicates the culture to foreigners. So that eventually, the culture will become extinct. (5) $A$ culture that is digested raw: The communication does not happen directly but through television or newspapers. Society, in general, will accept it outright, starting from following their daily lives and causing our daily lives to be based on their culture, not our own. (6) Art: If we talk about culture, then we will relate to the arts, with the papular culture entering the country through the media or what I am saying is modernization. Many made changes about the existing arts; the current arts began to be upgraded to become more modern. And that will have an impact on the loss of authenticity in art.

These fundamental cultural values are confronted with the dynamics of relationships that are mostly related to status factors and the role they play in the cultural group concerned. At a more relaxed layer, aspects of social norms derived from communication interactions with the environment will color individual cultural values. And at the level of social groups, many aspects of differences are accommodated by group members. A shared understanding of social facts that are directed at forming the character of a particular social group. Distinctive individual differences in cultural values are reduced by higher social group values. Thus, differences in personal cultural values are not expected to be a significant barrier to intercultural communication because of the many similarities they have. The cultural elements in question can be distinguished on belief systems, knowledge systems, arts, languages, social systems-economic policies and equipment such as technology.

\section{Conclusion}

Intercultural communication occurs when two or more people with different cultural backgrounds interact. These differences can be racial, ethnic, or socioeconomic differences. Three factors drive the development of intercultural communication, namely international, domestic, and individuals. Three essential principles of intercultural communication, namely: (1) a shared cipher system consisting of two aspects - verbal and nonverbal; (2) different beliefs and behavior among communicating parties; (3) the level of knowing and accepting the beliefs and behavior of others. Mass media, as one of the channels of intercultural communication, plays a role in constructive development in intercultural life in a format that encourages the acceleration of understanding of other cultural characters, increases the effectiveness of intercultural communication, and facilitates social interaction for cultural similarity. Mass media plays a role in developing, passing down, and preserving culture more broadly and openly.

\section{References}

[1] P. S. Criticism, "Philosophy \& Social Criticism," Philos. Soc. Crit., 2009, doi: 10.1177/019145379502100103.

[2] M. O’Sullivan, An enquiry concerning human understanding. 2017.

[3] D. S. Bassett and M. S. Gazzaniga, "Understanding complexity in the human brain," Trends in Cognitive Sciences. 2011, doi: 10.1016/j.tics.2011.03.006.

[4] G. Hall and G. Hall, "The Human," in Pirate Philosophy, 2017.

[5] D. Hume, “A TREATISE OF HUMAN NATURE,” in Hume's Ethical Writings, 2019. 
[6] T. M. Steinfatt and D. M. Millette, "Intercultural communication," in An Integrated Approach to Communication Theory and Research, Third Edition, 2019.

[7] C. Communication and L. Dongfeng, "Culture Shock and Its Implications for Cross-Cultural Training and Culture Teaching. ," Cross-Cultural Commun., 2012, doi: 10.3968/j.ccc.1923670020120804.1433.

[8] D. L. Medin and M. Bang, "The cultural side of science communication," Proc. Natl. Acad. Sci. U. S. A., 2014, doi: 10.1073/pnas.1317510111.

[9] C. B. Johnston, "Cross-Cultural Communication," in Encyclopedia of International Media and Communications, 2003.

[10] T. Luhuringbudi, M. D. Syamsuddin, and S. A. Hakim, "Activists communication dynamics for mobilization of minority politics in europe," Int. J. Commun. Soc., vol. 1, no. 2, pp. 43-57, Sep. 2019, doi: 10.31763/ijcs.v1i2.50.

[11] D. Kaplan, Anthropological Theory. 2017.

[12] S. J. Collier and A. Ong, "Global Assemblages Anthropological Problems," in Global Assemblages: Technology, Politics, and Ethics as Anthropological Problems, 2008.

[13] "A cultural approach to communication," in Communication as Culture: Essays on Media and Society: Revised Edition, 2008.

[14] H. Mowlana, "On Human Communication," Javnost, 2018, doi: 10.1080/13183222.2018.1418978.

[15] A. Agha, "The social life of cultural value," Lang. Commun., 2003, doi: 10.1016/S02715309(03)00012-0.

[16] D. Tannen, "The pragmatics of cross-cultural communication," Appl. Linguist., 1984, doi: 10.1093/applin/5.3.189.

[17] J. Hartley, Communication, Cultural and Media Studies: The Key Concepts. 2002.

[18] M. G. Durham and D. M. Kellner, "Media and cultural studies - keyworks," Media Cult. Stud., 2006, doi: $10.1177 / 026858094009002003$.

[19] A. V. Matveev and P. E. Nelson, "Cross cultural communication competence and multicultural team performance: Perceptions of American and Russian managers," Int. J. Cross Cult. Manag., 2004, doi: $10.1177 / 1470595804044752$.

[20] L. C. and B. Thakkar, "The Impact of Globalization on Cross-Cultural Communication," in Globalization - Education and Management Agendas, 2012.

[21] J. C. Richards and R. W. Schmidt, Language and communication. 2014.

[22] F. F. Lotan, "Making a positive internet through Socmed Agawe Guyub," Int. J. Commun. Soc., vol. 1, no. 1, pp. 9-16, 2019, doi: 10.31763/ijcs.v1i1.22.

[23] A. Presbitero, "Culture shock and reverse culture shock: The moderating role of cultural intelligence in international students' adaptation," Int. J. Intercult. Relations, vol. 53, pp. 28-38, Jul. 2016, doi: 10.1016/j.ijintrel.2016.05.004.

[24] D. Fadillah, Z. Nuryana, and S. -, "Public Opinion of the facial recognition policy in China by Indonesian Student in Nanjing City," Int. J. Psychosoc. Rehabil., vol. 24, no. 04, pp. 1645-1652, Feb. 2020, doi: 10.37200/IJPR/V24I4/PR201272.

[25] B. Nerlich, N. Koteyko, and B. Brown, "Theory and language of climate change communication," Wiley Interdisciplinary Reviews: Climate Change. 2010, doi: 10.1002/wcc.2.

[26] N. Evans and S. C. Levinson, "The myth of language universals: Language diversity and its importance for cognitive science," Behavioral and Brain Sciences. 2009, doi: 10.1017/S0140525X0999094X.

[27] A. S. Pollick and F. B. M. De Waal, "Ape gestures and language evolution," Proc. Natl. Acad. Sci. U. S. A., 2007, doi: 10.1073/pnas.0702624104.

[28] S. Hasenstab, R. F. Wetmore, and T. Eggleston, "Language development," in Complications in Pediatric Otolaryngology, 2005. 
[29] F. C. Lunenburg, "Communication: The Process, Barriers, And Improving Effectiveness,” Schooling, vol. 1, no. 1, pp. 1-11, 2010.

[30] M. Catrileo, "Intercultural Communication: A Reader," Estud. filológicos, 2004, doi: 10.4067/s007117132004003900019.

[31] R. Krieglmeyer and J. W. Sherman, "Disentangling stereotype activation and stereotype application in the stereotype misperception task,” J. Pers. Soc. Psychol., 2012, doi: 10.1037/a0028764.

[32] L. M. Baker, “Observation: A complex research method," Libr. Trends, 2006, doi: 10.1353/lib.2006.0045.

[33] Research Information Network, Library, and British Library, "Patterns of Information Use and Exchange: Case Studies of Researchers in the Life Sciences," Patterns Inf. use Exch. case Stud. Res. life Sci., 2009.

[34] G. Morán Debraine, “Le Visible et l'Invisible,” Textyles, 2018, doi: 10.4000/textyles.2802.

[35] E. W. Taylor, “Transformative learning theory," New Dir. Adult Contin. Educ., 2008, doi: 10.1002/ace.301.

[36] B. Malinowski, Argonauts of the western pacific: An account of native enterprise and adventure in the archipelagoes of Melanesian New Guinea. 2014. 